\title{
THREE STAGES OF COMPOSITE SPECIMEN DESTRUCTION IN STATIC FAILURE
}

\author{
M. Urbaha1*, I. Agafonovs², V. Turko ${ }^{3}$, J. Fescuks ${ }^{4}$ \\ 1,2,4 Latvian Maritime Academy, \\ 12 Flotes Str., Riga, LV-1016, LATVIA \\ ${ }^{3}$ Riga Technical University, \\ 1 Kalku Str., Riga, LV-1048, LATVIA \\ *e-mail: Margarita.Urbaha@latja.Iv
}

The paper presents the results of standard specimen fracture made of anisotropic carbon fiber plastic with an epoxy matrix. Static stepwise loading of the specimen was carried out on an Instron 8801 testing machine to determine the characteristics of ductile fracture $\mathrm{G}_{1 \mathrm{C}}$ in the first mode in accordance with ASTM D5528.

During loading, the parameters of acoustic emission (AE) signals, such as AE impulse amplitudes and their energy were synchronously recorded. At the same time, the magnitude of the opening and the growth of the crack initiated by the artificial cut at the end of the specimen were recorded.

According to the analysis of the acoustic emission signals, three zones with different $\mathrm{G}_{1 \mathrm{C}}$ behaviour were identified: initial crack propagation, its stationary growth and accelerated fracture of the specimen. The zonal character of the change in the acoustic emission signals made it possible to determine the energy of the acoustic emission signals as diagnostic evidence for the onset of rapid destruction of the specimen.

The amplitude of the AE-signals in the zones, however, remained constant. Online monitoring of changes in the energy of acoustic emission signals will prevent the onset of rapid destruction of an object in places of its deformations. The paper does not aim at defining $\mathrm{G}_{1 \mathrm{C}}$ as usual. It presents the investigation of the fracture stages for a composite material using an acoustic emission method.

Keywords: Acoustic emission data analysis, carbon fiber, composite specimen destruction. 


\section{INTRODUCTION}

The paper deals with the determination of opening Mode I interlaminar fracture toughness, $G_{\mathrm{I}} \mathrm{c}$, for continuous fiberreinforced composite materials using the double cantilever beam (DCB) specimen. During testing, an acoustic emission (AE) method was applied to obtain experimental data. $G_{\mathrm{I}} \mathrm{c}$ calculation was performed in compliance with ASTM D5528 [1] using a method of Modified Beam Theory (MBT) (Fig. 1).
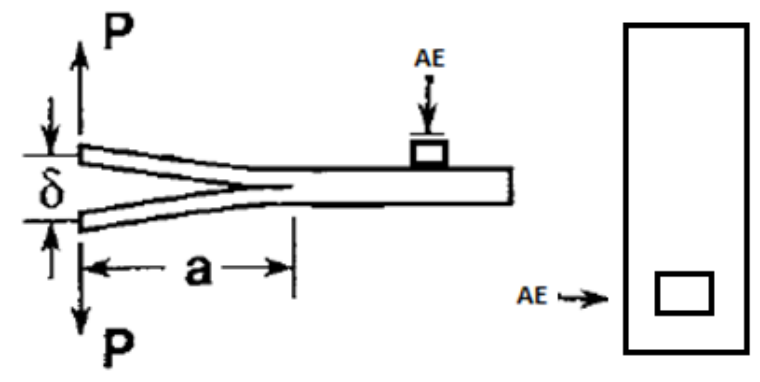

Fig. 1. Scheme of determination of G1c according to ASTM D5528.

where $\mathrm{P}$ - load, $\mathrm{N} ; \delta$ - crack opening, $\mathrm{mm} ; \mathrm{b}$ - specimen width, $\mathrm{mm}$; $\mathrm{a}$ - crack length, $\mathrm{mm}$; $\mathrm{AE}-$ acoustic emission gauge.

\section{EXPERIMENTAL}

Specimens were made of carbon fiber zero-degree orientation (see Fig. 2). On the both sides, metallic hinges have been glued to transfer load during loading. The dimensions of specimens are $200 \mathrm{~mm} \times 25 \mathrm{~mm}$ x $3 \mathrm{~mm}$. Before testing, in each specimen cleavage about $50 \mathrm{~mm}$ was made as crack initiator with utility knife. The Instron 8801 machine was used for specimen stepwise loading (loading-unloading). The Instron $8801100 \mathrm{kN}$ is a compact servo hydraulic fatigue testing system that meets the challenging demands of various static and dynamic testing requirements. 8801 systems provide complete testing solutions to satisfy the needs of advanced materials and component testing, and are ideally suited for fatigue testing and fracture mechanics [2]. For measurement crack length and crack opening, digital caliper was used [3]. During testing, Vallen system AMSY-6 digital multi-channel acoustic emission (AE) acquisition system was used. Vallen AMSY-6 is a fully digital multi-channel AE measurement system. A measurement channel consists of an $\mathrm{AE}$ sensor, preamplifier and one channel of an ASIP-2 (dual channel acoustic signal processor). Each channel combines an analogue measurement section and a digital signal processing unit. $\mathrm{AE}$ features, such as time of the first threshold crossing (arrival time), rise time, duration, peak amplitude, energy and counts, are extracted by the ASIP-2 [4]. According to the procedure, the calibration was performed using a standardized source of HsuNielsen (Hsu-Nielsen source). In this case, the threshold value was $30.1 \mathrm{~dB}$ [5]. 
The AMSY-6 provides four types of measurement data:

- Hit data: data that are generated when the AE signal exceeds the threshold;

- Status data: data that are generated in regular time intervals;

- Parametric data: data of external para- metric sensors which are measured at regular time intervals. Parametric data are stored with every hit and at userspecified time intervals;

- Waveform data: sampled AE sensor signal.

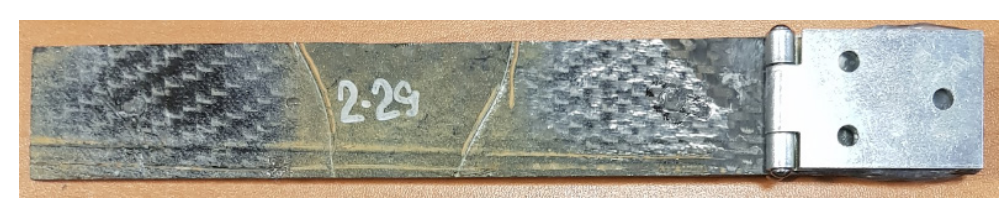

Fig. 2. General view of specimen.

\section{RESULTS AND DISCUSSION}

The results of loading and measure- mens (see Table 1). ments are averaged values over three speci-

Table 1. The Results of Loading and Measurements

\begin{tabular}{|l|c|c|c|c|c|}
\hline Average load, N & $\begin{array}{c}\text { Average crack } \\
\text { opening, mm }\end{array}$ & $\begin{array}{c}\text { Average crack } \\
\text { length, mm }\end{array}$ & Average $\mathrm{G}_{1 \mathrm{C}}$, & $\begin{array}{c}\text { Average AE } \\
\text { Energy, J }\end{array}$ & $\begin{array}{c}\text { Average ampli- } \\
\text { tude, A }\end{array}$ \\
\hline 0 & 0.00 & 50.91 & 0.00 & 27643 & 69.3 \\
\hline 48 & 5.83 & 52.07 & 0.27 & 829802 & 83.6 \\
\hline 69 & 7.57 & 54.04 & 0.50 & 1835112 & 94.8 \\
\hline 77 & 8.62 & 55.58 & 0.61 & 8001274 & 95.9 \\
\hline 68 & 10.18 & 58.93 & 0.60 & 32349678 & 100.0 \\
\hline 65 & 11.34 & 60.51 & 0.62 & 17617166 & 100.0 \\
\hline 59 & 12.59 & 64.88 & 0.58 & 2101359 & 96.0 \\
\hline 51 & 13.92 & 66.19 & 0.55 & 11062139 & 100.0 \\
\hline 51 & 15.42 & 67.96 & 0.58 & 8762451 & 99.8 \\
\hline 45 & 17.47 & 70.97 & 0.56 & 18522012 & 100.0 \\
\hline 39 & 19.57 & 76.21 & 0.51 & 6130811 & 86.3 \\
\hline 36 & 20.88 & 78.73 & 0.48 & 802792 & 92.2 \\
\hline 31 & 23.93 & 82.68 & 0.46 & 4653842 & 99.1 \\
\hline 29 & 27.03 & 87.22 & 0.45 & 6168770 & 100.0 \\
\hline 26 & 30.46 & 92.14 & 0.44 & 11803327 & 100.0 \\
\hline 25 & 32.98 & 95.21 & 0.44 & 4050307 & 86.4 \\
\hline 12 & 37.77 & 102.50 & 0.33 & 635252 & 81.7 \\
\hline 9 & 42.30 & 103.60 & 0.19 & 32199243 & 100.0 \\
\hline
\end{tabular}


Energy is given in energy units (eu) and the software takes the selected gain into account, when calculating and displaying energy. Energy is calculated by squaring the digitized AE signal and integrating the results during the hit. 1 eu corresponds to $10^{-14} \mathrm{~V}^{2} \mathrm{sec}$ at the sensor output [6]. Energy is processed in either the so-called true energy mode or a signal strength mode. In both modes, energy is given in energy units and the software takes the selected gain into account, when calculating and displaying energy. Energy is stored in a logarithm format with a resolution of $0.1 \%$.

Figure 3 shows the change in $G_{\text {IC }}$ with loads.

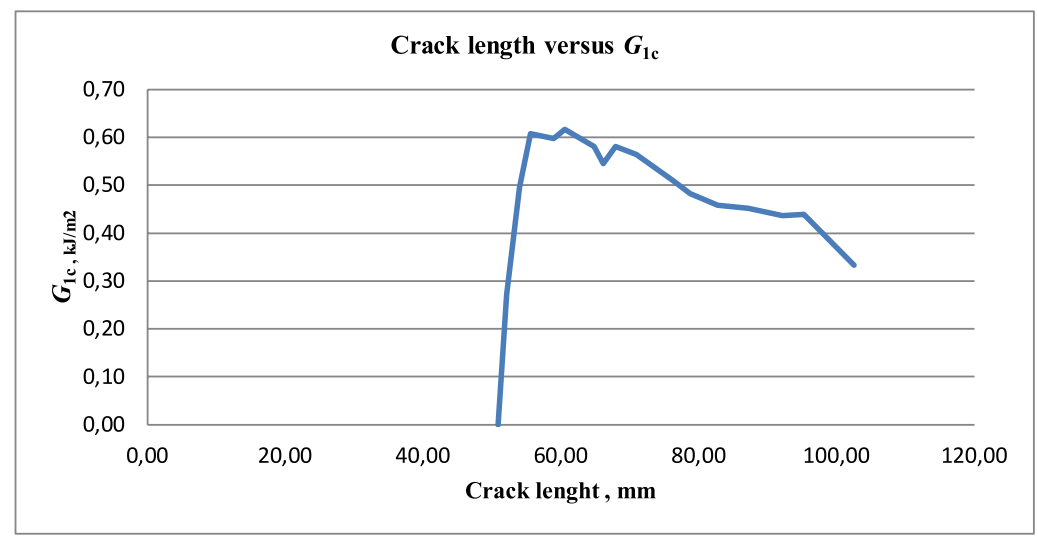

Fig. 3. The change in the fracture toughness in Mode 1 in the load.

A characteristic change in fracture toughness is observed during an increase in the load [7]. Due to a non-monotonic increase in the fracture toughness value, it is very difficult to determine the moment of termination of loading for its calculation.
Figure 4 demonstrates a comparison of the change in crack opening and crack length. An increase in crack opening and crack length depends on the loading. After maximal load cracks continue increasing, but the loads decrease.

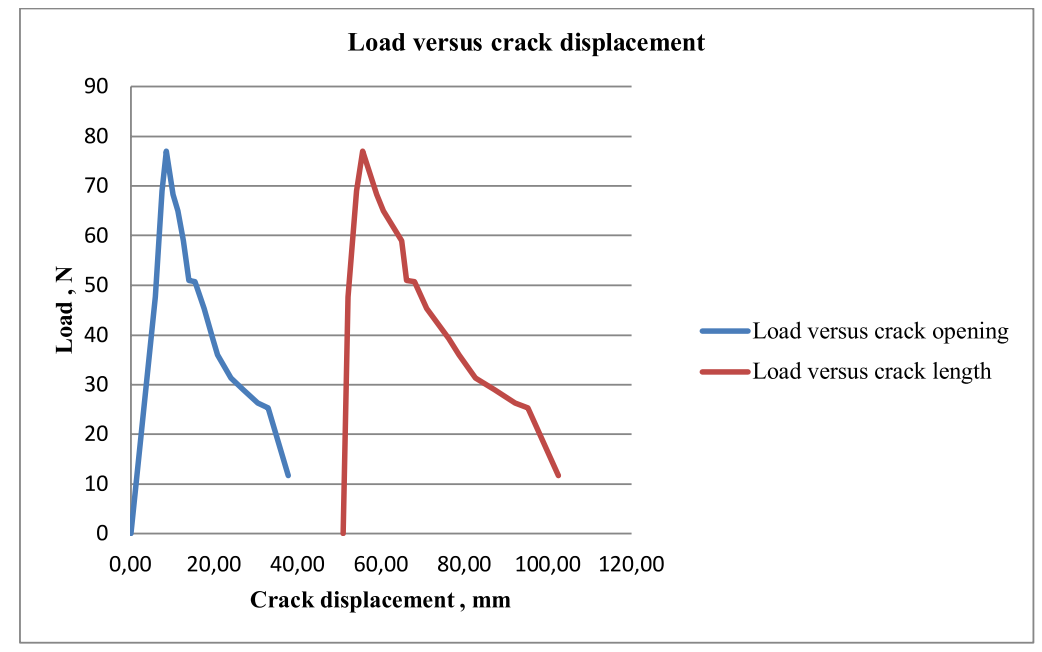

Fig. 4. The change in crack opening and crack length evolution during loading. 
As the probable moment of specimen destruction cannot be predicted exactly and crack opening is difficult to measure on a real object, there is a problem related to the operation of instrumental control over the beginning of accelerated destruction of the specimen [8].

Let us consider the changes in the parameters of acoustic emission signals under loading of the specimens. The use of the acoustic emission method for fullscale bench tests of aircraft structures and/ or their components shows that this method is the most effective and convenient to use for monitoring the technical state of the controlled object [9]-[13]. This integrated method allows monitoring a rather extensive area free of NDT Operator in the online regime [14]. When diagnostic signs of incipient fracture appear, it becomes possible for the Operator to periodically use other methods of instrumental control of a suspicious area, but already in specific places of destruction [15], [16].

Table 2 shows loading stages for each measurement channel.

Table 2. Three Stages of Composite Specimen Destruction

\begin{tabular}{|l|r|r|r|}
\hline Recording parameter & Initial zone, $\mathrm{P}$ & Increasing zone, $\mathrm{P}$ & Destruction zone, $\mathrm{P}$ \\
\hline $\mathrm{G}_{1 \mathrm{c}}$, & & & \\
\hline Crack opening, $\mathrm{mm}$ & $0-48 \mathrm{~N}$ & $48-12 \mathrm{~N}$ & $12-9 \mathrm{~N}$ \\
\hline Crack length, $\mathrm{mm}$ & & & \\
\hline AE energy, eu & & & \\
\hline AE amplitude, $\mathrm{A}$ & & & \\
\hline
\end{tabular}

Figure 5 shows changes in the AE strates changes in the AE energy and $\mathrm{G}_{1 \mathrm{C}^{*}}$. energy and amplitude, and Fig. 6 demon-

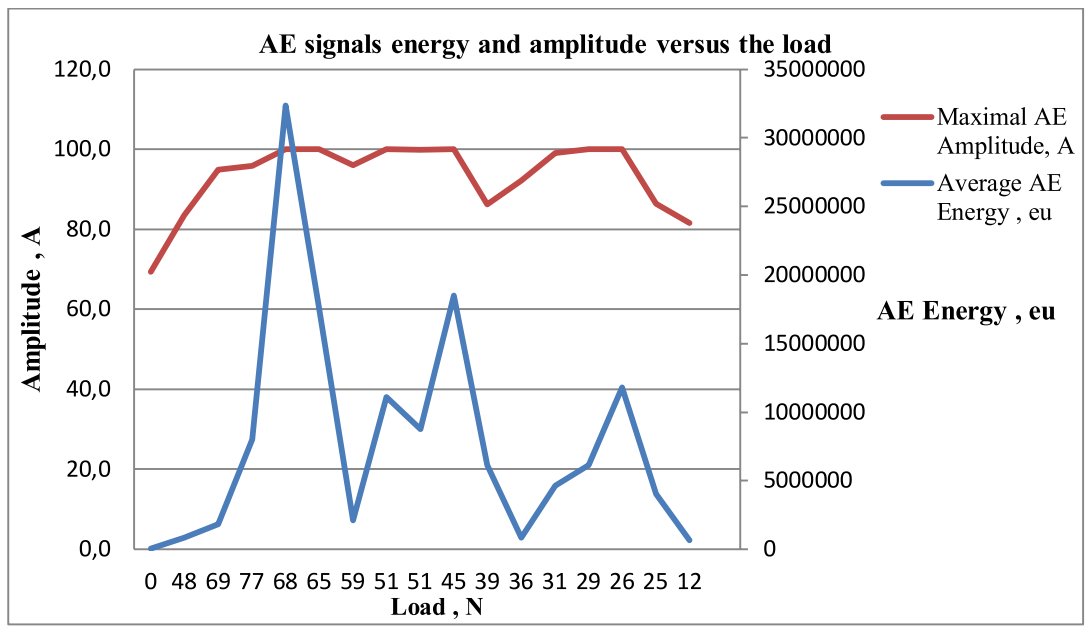

Fig. 5. Changes in AE energy and amplitude versus the load. 


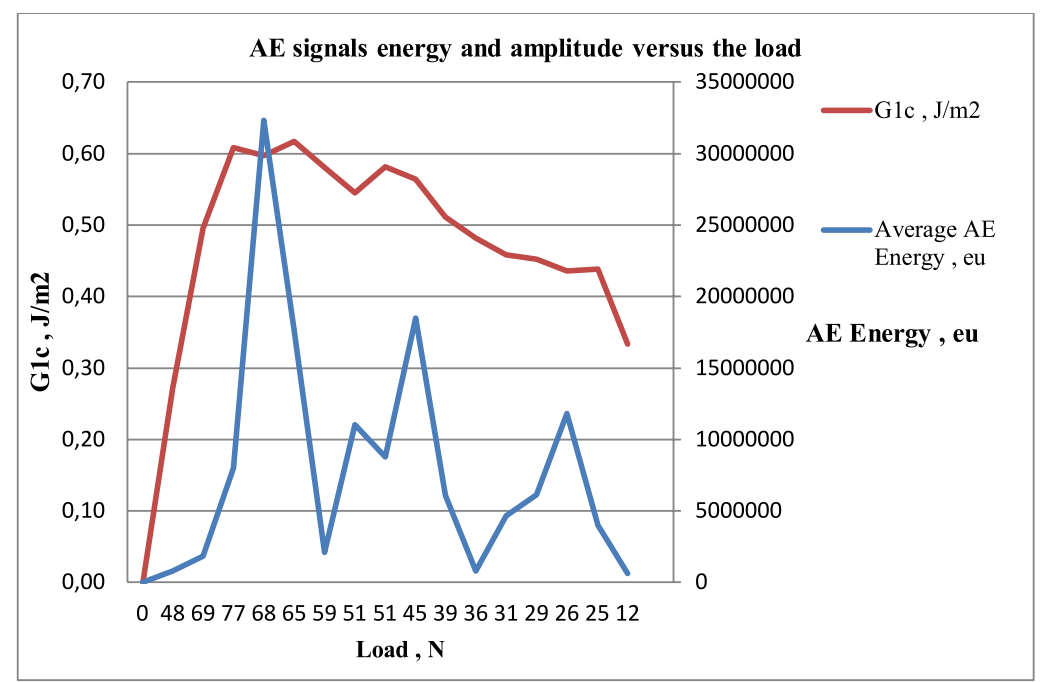

Fig. 6. Changes in AE energy depending on the $\mathrm{G}_{1 \mathrm{C}}$.

Figures 5 and 6 clearly show three zones of successive destruction of the composite material of the specimens. Thus, it is possible to objectively record the moment of the onset of accelerated destruction of the specimen. The most pronounced criterion here is the change in the energy of acoustic emission signals, while the maximum amplitude of the AE signals does not so characteristically record this moment.

\section{CONCLUSIONS}

The investigation of the fracture toughness of Mode 1 allows observing the moment of decreased loading. However, this moment is determined subjectively, and then impossibility of withstanding the load or its fall occurs. The research has shown that the nature of the sequential fracture of the composite material of standard specimen with a longitudinal cut is characterised by three zones: initial (from the moment the crack starts to move in the cut), stationary, and accelerated.

On-line acoustic emission monitoring of specimen fracture made it possible to objectively observe these zones and showed that the main diagnostic criterion was the energy of the acoustic emission signal. Thus, it will be possible to use this method in real designs subjected to deformations. The use of the acoustic emission method allows predicting the start and accelerated destruction of the weak elements. The composite products and structures during their deformations give objective information to Health and Usage Monitoring Systems.

\section{ACKNOWLEDGEMENTS}

The research has been supported by the European Regional Development Fund within Measure 1.1.1.2 "Aid to Post-Doc- toral Research" of the Specific Aid Objective "To increase the research and innovative capacity of scientific institutions of 
Latvia and the ability to attract external financing, investing in human resources and infrastructure" of the Operational Programme "Growth and Employment" (No.
1.1.1.2/VIAA/1/16/104 Structural Health Monitoring System for Inflight Monitoring (FLY SAFE System).

\section{REFERENCES}

1. Standard Test Method for Mode I Interlaminar Fracture Toughness of Unidirectional Fiber-Reinforced Polymer Matrix Composites. (n.d.) Available at https://www.astm.org/Standards/D5528

2. $8801(100 \mathrm{kN})$ Fatigue Testing Systems. (n.d.). Available at https://www.instron. us/products/testing-systems/dynamic-andfatigue-systems/servohydraulic-fatigue/8801floor-model

3. Lingelli, A. F. (Ed.) (2009). Fatigue Crack Growth. Mechanics, Behaviour and Prediction. New York: Nova Science Publishers Ins.

4. Multi-Channel Systems. (n.d.). Available at https://www.vallen.de/products/multichannel-systems/

5. Hsu-Nielsen Source. (n.d.). Available at https://www.ndt.net/article/az/ae/ hsunielsensource.htm

6. AMSY-5 System Description. (n.d.). Available at https://www.vallen.de/ zdownload/pdf/y5sd0911.pdf

7. Urbaha, M., Turko, V., Agafonovs, I., \& Sorokins, A. (2020). Experimental Evaluation of Static and Fatigue Strength of Aluminium-Based Structural Metallic Alloys. Engineering for Rural Development, 19, 487-493.

8. P.E.Mix Introduction to Non-destructive Testing, training guide (2nd ed.). (2005). New Jersey: John Wiley \& Sons, Inc.

9. Urbaha, M., Carjova, K., Nagaraj, P., \& Turko, V. (2018). Requirements for helicopter's planer construction fatigue testing. In Transport Means - Proceedings of the International Conference, (pp. 1268-1270), 3-5 October 2018, Trakai, Lithuania.

10. Urbahs, A., Banovs, M., Turko, V., Urbaha, M., Nedelko, D., \& Lebedevs, I. (2019).
Research into the features of service damage in the composite material of helicopter rotor blades. In Transport Means - Proceedings of the International Conference, (pp. 466469), 2-4 October 2019, Kaunas, Lithuania.

11. Гузь А.Н., Хорошун Л.П., Ванин Г.А., Бабич И.Ю., Каминский А.А., Шульга Н.А., Маслов Б.П., \& Скиченко А.В. (1982). Механика композитных материалов и элементов конструкций. Киев: Наук. думка.

12. Finlayson, R.D., Friesel, M., Carlos, M., Cole, P., \& Lenein, J.C. (2001). Health monitoring of aerospace structures with acoustic emission and acousto-ultrasonics. In 15th World Conference on NDT, 15-21 October, 2000, Rome, Italy. INSIGHT,43 (3).

13. Фейгенбаум Ю.М., Дубинский С.В., Божевалов Д.Г., Соколов Ю.С., Метелкин Е.С., Миколайчук Ю.А., \& Шапкин В.С. (2018). Обеспечение прочности композиционных авиационных конструкций с учетом случайных эксплуатационных ударных воздействий. $\quad M$.: Tехносфера.

14. Prostaks, J., \& Urbaha, M. (2019). Evaluating Accuracy of Fault Localization when Monitoring Condition of Large Structures by Acoustic Method. Engineering for Rural Development, 18, 1280-1286.

15. Nedelko, D., Urbahs, A., Turko, V., Urbaha, M., Carjova, K., \& Nagaraj, P. (2019). Assessment of the Limits of Signs of Health and Usage Monitoring System for Helicopter Transmission. Procedia Computer Science, 149, 252-257.

16. Turko, V. (2015). Principle of Local Zones Applied to Fatigue Prone Large-scale Designs. Lambert Academic Publishing. DOI: 10.22616/ERDev2020.19.TF111 